\title{
Updates on cardiovascular outcome trials in diabetes
}

\author{
Oliver Schnell ${ }^{1 *}$, Lars Rydén², Eberhard Standl ${ }^{1}$, Antonio Ceriello ${ }^{3,4}$ \\ and on behalf of the D\&CVD EASD Study Group
}

\begin{abstract}
In 2008 the Food and Drug Administration introduced a guidance for industry that requires the investigation of cardiovascular outcomes of glucose-lowering medications. Since then, an increasing number of cardiovascular outcome trials have been completed in diabetes patients with high cardiovascular risk for members of the SGLT-2 and DPP4 inhibitors and GLP-1 receptor agonist classes. The trials confirmed cardiovascular safety for all tested anti-hyperglycaemic drugs and, in addition empagliflozin, semaglutide and liraglutide could even reduce cardiovascular risk. The present review summarizes the results of the DEVOTE, CANVAS, EXSCEL and ACE trials that tested cardiovascular safety of Insulin degludec, canagliflozin, once-weekly exenatide and acarbose and were published in 2017. We provide context on these results by comparing them with earlier trials of glucose-lowering drugs and give an outlook on what to expect in coming years.
\end{abstract}

Keywords: Cardiovascular risk, Diabetes, CVOT, DEVOTE, CANVAS program, EXSCEL, ACE, Heart

\section{Background}

Patients with diabetes have a much higher risk of cardiovascular $(\mathrm{CV})$ disease $(\mathrm{CVD})$ than individuals without diabetes [1]. This up to $50 \%$ increased risk of CV-related death is one of the major causes of mortality [2]. Studies could show, that good glycaemic control can positively influence the long-term development of CVD and mortality $[3,4]$. Thus, CV safety and benefits of glucose-lowering medications have been the focus of recent studies. Accordingly, the Food and Drug Administration (FDA) and the European Medicines Agency (EMA) presented a guidance for the approval of glucose-lowering medications in 2008 and 2012, respectively [5, 6]. This guidance requires the assessment of $\mathrm{CV}$ safety: if the pre-marketing application data revealed a hazard ratio (HR) with an upper 95\% confidence interval (CI) between 1.3 and 1.8 , a post-marketing trial will generally be necessary to demonstrate an upper $95 \% \mathrm{CI}$ of $<1.3$. Does the premarketing clinical data already demonstrate an upper

\footnotetext{
*Correspondence: oliver.schnell@|rz.uni-muenchen.de

${ }^{1}$ Forschergruppe Diabetes e. V., Ingolstaedter Landstraße 1, Neuherberg, 85764 Munich, Germany

Full list of author information is available at the end of the article
}

$95 \% \mathrm{CI}$ of $<1.3$, the post-marketing trial can be neglected $[5,7]$. Since issuing the abovementioned guidelines, several major CV outcome trials (CVOTs) had been completed until 2016. These included glucose-lowering medications of the DPP-4 (3 studies: SAVOR-TIMI53, EXAMINE and TECOS) and SGLT-2 inhibitor (1 study: EMPA-REG OUTCOME) as well as GLP-1 receptor agonist (RA; 3 studies: ELIXA, LEADER and SUSTAIN6) classes [8]. Also Insulin glargine and Insulin degludec had been subjected to be tested for CV safety [9-11].

The previously published CVOTs determined safety of the DPP-4 inhibitors saxagliptin, alogliptin and sitagliptin as well as the GLP-1 RA lixisenatide with regard to CV outcomes [12-15]. Additionally, LEADER, SUSTAIN6 and EMPA-REG OUTCOME could show the capability of liraglutide, semaglutide and empagliflozin to reduce CV outcomes in diabetes patients with high CV risk [1618]. The D\&CVD EASD Study Group recently gave an overview of these CVOTs, and discussed future perspectives for the treatment of patient with diabetes (Tables 1, 2 and $3 ;[8])$.

Here we present an update of this publication, including the most recent CVOTs on GLP-1 RAs, SGLT-2 inhibitors, Insulin degludec and acarbose and discuss 
Table 1 Basic characteristics of CVOTs started after 2008 FDA regulation

\begin{tabular}{|c|c|c|c|c|c|c|c|c|c|}
\hline & Study status & Drug & Drug class & Intervention & $\begin{array}{l}\text { Primary } \\
\text { outcome }\end{array}$ & $\mathrm{N}$ & $\begin{array}{l}\text { Follow-up } \\
\text { (years) }\end{array}$ & $\begin{array}{l}\text { Start } \\
\text { and esti- } \\
\text { mated end } \\
\text { date }\end{array}$ & $\begin{array}{l}\text { Clinicaltrials. } \\
\text { gov ID }\end{array}$ \\
\hline SAVOR-TIMI53 & Completed & Saxagliptin & $\begin{array}{l}\text { DPP-4 inhibi- } \\
\text { tor }\end{array}$ & $\begin{array}{l}\text { Addition of } \\
\text { saxagliptin } \\
\text { vs. placebo } \\
\text { to usual dia- } \\
\text { betes care }\end{array}$ & $\begin{array}{l}\text { CV death, Ml, } \\
\text { or stroke }\end{array}$ & 18,206 & 2.1 & $\begin{array}{l}05.2010- \\
05.2013\end{array}$ & NCT01107886 \\
\hline EXAMINE & Completed & Alogliptin & $\begin{array}{l}\text { DPP-4 inhibi- } \\
\text { tor }\end{array}$ & $\begin{array}{l}\text { Addition of } \\
\text { alogliptin } \\
\text { vs. placebo } \\
\text { to usual dia- } \\
\text { betes care }\end{array}$ & $\begin{array}{l}\text { CV death, } \mathrm{Ml} \text {, } \\
\text { or stroke }\end{array}$ & 5380 & 1.5 & $\begin{array}{l}10.2009- \\
06.2013\end{array}$ & NCT00968708 \\
\hline TECOS & Completed & Sitagliptin & $\begin{array}{l}\text { DPP-4 inhibi- } \\
\text { tor }\end{array}$ & $\begin{array}{l}\text { Sitagliptin vs. } \\
\text { placebo }\end{array}$ & $\begin{array}{l}\text { CV death, } \\
\text { MI, UA, or } \\
\text { stroke }\end{array}$ & 14,724 & 3 & $\begin{array}{l}12.2008- \\
03.2015\end{array}$ & NCT00790205 \\
\hline ELIXA & Completed & Lixisenatide & $\begin{array}{l}\text { GLP-1 receptor } \\
\text { agonist }\end{array}$ & $\begin{array}{l}\text { Lixisenatide } \\
\text { vs. placebo }\end{array}$ & $\begin{array}{l}\text { CV death, } \\
\text { MI, UA, or } \\
\text { stroke }\end{array}$ & 6076 & 2.1 & $\begin{array}{l}06.2010- \\
02.2015\end{array}$ & NCT01147250 \\
\hline $\begin{array}{l}\text { EMPA-REG } \\
\text { OUTCOME }\end{array}$ & Completed & Empagliflozin & $\begin{array}{l}\text { SGLT-2 inhibi- } \\
\text { tor }\end{array}$ & $\begin{array}{l}\text { Empagliflozin } \\
10 \text { mg vs. } \\
\text { empagliflo- } \\
\text { zin } 25 \text { mg } \\
\text { vs. placebo }\end{array}$ & $\begin{array}{l}\text { CV death, Ml, } \\
\text { or stroke }\end{array}$ & 7000 & 3.1 & $\begin{array}{l}07.2010- \\
04.2015\end{array}$ & NCT01131676 \\
\hline LEADER & Completed & Liraglutide & $\begin{array}{l}\text { GLP-1 receptor } \\
\text { agonist }\end{array}$ & $\begin{array}{l}\text { Liraglutide vs. } \\
\text { placebo }\end{array}$ & $\begin{array}{l}\text { CV death, } \mathrm{Ml} \text {, } \\
\text { or stroke }\end{array}$ & 9340 & 3.8 & $\begin{array}{l}08.2010- \\
12.2015\end{array}$ & NCT01179048 \\
\hline SUSTAIN-6 & Completed & Semaglutide & $\begin{array}{l}\text { GLP-1 receptor } \\
\text { agonist }\end{array}$ & $\begin{array}{l}\text { Semaglutide } \\
0.5 \mathrm{mg} \text { vs. } \\
\text { semaglu- } \\
\text { tide } 1.0 \mathrm{mg} \\
\text { vs. placebo }\end{array}$ & $\begin{array}{l}\text { CV death, } \mathrm{Ml} \text {, } \\
\text { or stroke }\end{array}$ & 3299 & 1.9 & $\begin{array}{l}02.2013- \\
01.2016\end{array}$ & NCT01720446 \\
\hline EXSCEL & Completed & Exenatide & $\begin{array}{l}\text { GLP-1 receptor } \\
\text { agonist }\end{array}$ & $\begin{array}{l}\text { Exenatide } \\
\text { once- } \\
\text { weekly vs. } \\
\text { placebo }\end{array}$ & $\begin{array}{l}\text { CV death, Ml, } \\
\text { or stroke }\end{array}$ & 14,752 & 3.2 & $\begin{array}{l}06.2010- \\
04.2017\end{array}$ & NCT01144338 \\
\hline CAROLINA & $\begin{array}{l}\text { Ongoing, not } \\
\text { recruiting }\end{array}$ & Linagliptin & $\begin{array}{l}\text { DPP-4 inhibi- } \\
\text { tor }\end{array}$ & $\begin{array}{l}\text { Linagliptin } \\
\text { vs. sulfony- } \\
\text { lureas vs. } \\
\text { placebo }\end{array}$ & $\begin{array}{l}\text { CV death, } \\
\text { MI, UA, or } \\
\text { stroke }\end{array}$ & 6000 & - & $\begin{array}{l}10.2010- \\
03.2019\end{array}$ & NCT01243424 \\
\hline REWIND & $\begin{array}{l}\text { Ongoing, not } \\
\text { recruiting }\end{array}$ & Dulaglutide & $\begin{array}{l}\text { GLP-1 receptor } \\
\text { agonist }\end{array}$ & $\begin{array}{l}\text { Dulaglutide } \\
\text { vs. placebo }\end{array}$ & $\begin{array}{l}\text { CV death, Ml, } \\
\text { or stroke }\end{array}$ & 9622 & - & $\begin{array}{l}07.2011- \\
07.2018\end{array}$ & NCT01394952 \\
\hline ITCA650 & Completed & $\begin{array}{l}\text { Exenatide in } \\
\text { DUROS }\end{array}$ & $\begin{array}{l}\text { GLP-1 receptor } \\
\text { agonist }\end{array}$ & $\begin{array}{l}\text { ITCA } 650 \\
\text { (exenatide } \\
\text { in DUROS) } \\
\text { vs. placebo }\end{array}$ & $\begin{array}{l}\text { CV death, } \\
\text { MI, UA, or } \\
\text { stroke }\end{array}$ & 4000 & - & $\begin{array}{l}03.2013- \\
03.2016\end{array}$ & NCT01455896 \\
\hline DECLARE-TIMI & $\begin{array}{l}\text { Ongoing, not } \\
\text { recruiting }\end{array}$ & Dapagliflozin & $\begin{array}{l}\text { SGLT-2 inhibi- } \\
\text { tor }\end{array}$ & $\begin{array}{c}\text { Dapagliflozin } \\
10 \text { mg vs. } \\
\text { placebo }\end{array}$ & $\begin{array}{l}\text { CV death, MI, } \\
\text { or stroke }\end{array}$ & 17,276 & - & $\begin{array}{l}01.2013- \\
04.2019\end{array}$ & NCT01730534 \\
\hline CARMELINA & $\begin{array}{l}\text { Ongoing, not } \\
\text { recruiting }\end{array}$ & Linagliptin & $\begin{array}{l}\text { DPP-4 inhibi- } \\
\text { tor }\end{array}$ & $\begin{array}{l}\text { Linagliptin vs. } \\
\text { placebo }\end{array}$ & $\begin{array}{l}\text { CV death, } \\
\text { MI, UA, or } \\
\text { stroke }\end{array}$ & 8000 & - & $\begin{array}{l}07.2013- \\
12.2017\end{array}$ & NCT01897532 \\
\hline DEVOTE & Completed & $\begin{array}{l}\text { Insulin deglu- } \\
\text { dec }\end{array}$ & Basal insulins & $\begin{array}{l}\text { Insulin } \\
\text { degludec } \\
\text { vs. insulin } \\
\text { glargine }\end{array}$ & $\begin{array}{l}\text { CV death, Ml, } \\
\text { or stroke }\end{array}$ & 7637 & 1.9 & $\begin{array}{l}10.2013- \\
10.2016\end{array}$ & NCT01959529 \\
\hline MK-3102 & Terminated & MK-3102 & $\begin{array}{l}\text { DPP-4 inhibi- } \\
\text { tor }\end{array}$ & $\begin{array}{c}\text { MK-3102 vs. } \\
\text { placebo }\end{array}$ & $\begin{array}{l}\text { CV death, } \\
\text { MI, UA, or } \\
\text { stroke }\end{array}$ & 4202 & - & $\begin{array}{l}10.2012- \\
03.2017\end{array}$ & NCT01703208 \\
\hline
\end{tabular}


Table 1 continued

\begin{tabular}{|c|c|c|c|c|c|c|c|c|c|}
\hline & Study status & Drug & Drug class & Intervention & $\begin{array}{l}\text { Primary } \\
\text { outcome }\end{array}$ & $N$ & $\begin{array}{l}\text { Follow-up } \\
\text { (years) }\end{array}$ & $\begin{array}{l}\text { Start } \\
\text { and esti- } \\
\text { mated end } \\
\text { date }\end{array}$ & $\begin{array}{l}\text { Clinicaltrials. } \\
\text { gov ID }\end{array}$ \\
\hline VERTIS & $\begin{array}{l}\text { Ongoing, not } \\
\text { recruiting }\end{array}$ & Ertugliflozin & $\begin{array}{l}\text { SGLT-2 inhibi- } \\
\text { tor }\end{array}$ & $\begin{array}{l}\text { Ertugliflozin } \\
5 \text { mg vs. } \\
\text { ertugliflozin } \\
15 \text { mg vs. } \\
\text { placebo }\end{array}$ & $\begin{array}{l}\text { CV death, } \mathrm{MI} \text {, } \\
\text { or stroke }\end{array}$ & 3900 & - & $\begin{array}{l}11.2013- \\
10.2019\end{array}$ & NCT01986881 \\
\hline $\begin{array}{l}\text { CANVAS } \\
\text { program }\end{array}$ & Completed & Canagliflozin & $\begin{array}{l}\text { SGLT-2 inhibi- } \\
\text { tor }\end{array}$ & $\begin{array}{l}\text { Canagliflozin } \\
100 \text { mg vs. } \\
\text { canagliflo- } \\
\text { zin } 300 \text { mg } \\
\text { vs. placebo }\end{array}$ & $\begin{array}{l}\mathrm{CV} \text { death, } \mathrm{Ml} \\
\text { or stroke }\end{array}$ & 10,142 & 1.5 & $\begin{array}{l}12.2009- \\
02.2017\end{array}$ & NCT01032629 \\
\hline $\begin{array}{l}\text { Albiglutide } \\
\text { trial }\end{array}$ & $\begin{array}{l}\text { Ongoing, not } \\
\text { recruiting }\end{array}$ & Albiglutide & $\begin{array}{l}\text { GLP-1 receptor } \\
\text { agonist }\end{array}$ & $\begin{array}{l}\text { Albiglutide } \\
30 \text { mg vs. } \\
\text { albiglutide } \\
50 \text { mg vs. } \\
\text { placebo }\end{array}$ & $\begin{array}{l}\text { CV death, } \mathrm{Ml} \\
\text { or stroke }\end{array}$ & 9400 & - & $\begin{array}{l}07.2015- \\
02.2018\end{array}$ & NCT02465515 \\
\hline ACE & Completed & Acarbose & $\begin{array}{l}\text { a-Glucosidase } \\
\text { inhibitor }\end{array}$ & $\begin{array}{l}\text { Acarbose vs. } \\
\text { placebo }\end{array}$ & $\begin{array}{l}\text { CV death, Ml } \\
\text { or stroke }\end{array}$ & 6522 & 5.0 & $\begin{array}{l}02.2009- \\
04.2017\end{array}$ & NCT00829660 \\
\hline
\end{tabular}

Table 2 Inclusion criteria of patients enrolled in CVOTs referred to in the text

\begin{tabular}{|c|c|c|c|c|c|c|}
\hline & Age & Diabetes type & HbA1c levels & Cardiovascular status & $\begin{array}{l}\text { Prior anti hyperglycaemic } \\
\text { treatment }\end{array}$ & BMI $\left(\mathrm{Kg} / \mathrm{m}^{2}\right)$ \\
\hline SAVOR-TIMI53 & $\geq 40$ & T2DM & $\geq 6.5 \%$ & CVD or high CV risk & $\mathrm{AHA}$ & 31.1 \\
\hline EXAMINE & $\geq 18$ & T2DM & $(6.5,11.0 \%)$ & $\operatorname{ACS}(15,90)$ days before & $\mathrm{AHA}$ & 28.7 \\
\hline TECOS & $\geq 50$ & T2DM & $(6.5,8.0 \%)$ & pre-existing CVD & $\mathrm{AHA}$ & 30.2 \\
\hline ELIXA & $\geq 30$ & T2DM & $\geq 7.0 \%$ & ACS min. 180 days before & $\mathrm{AHA}$ & 30.2 \\
\hline EMPA-REG OUTCOME & $\geq 18$ & T2DM & $(7.0,10.0 \%)$ & Pre-existing CVD & Drug naive or AHA & $\leq 45$ \\
\hline LEADER & $\geq 50$ & T2DM & $\geq 7.0 \%$ & $\begin{array}{l}\text { Pre-existing CVD/cerebrovascu- } \\
\text { lar disease/vascular disease/ } \\
\text { renal or heart failure at } \geq 50 \\
\text { or CV risk at } \geq 60\end{array}$ & Drug naive or AHA & 32.5 \\
\hline SUSTAIN6 & $\geq 50$ & T2DM & $\geq 7.0 \%$ & $\begin{array}{l}\text { Pre-existing CVD at } \geq 50 \text { OR } \\
\text { pre-CVD at } \geq 60\end{array}$ & Drug naive or AHA & 31.1 \\
\hline EXSCEL & $\geq 18$ & T2DM & $6.5-10.0 \%$ & $73.1 \%$ with previous CVD & Specific AHA & - \\
\hline CAROLINA & $\geq 40 \leq 85$ & T2DM & $(6.5,7.5-8.5 \%)$ & $\begin{array}{l}\text { CVD or specified diabetes } \\
\text { end-organ damage or } \\
\text { age } \geq 70 \text { years or } \geq 2 \text { speci- } \\
\text { fied } C V \text { risk factors }\end{array}$ & - & $\leq 45$ \\
\hline REWIND & $\geq 50$ & T2DM & $\leq 9.5 \%$ & $\begin{array}{l}\text { Pre-existing vascular disease } \\
\text { or } \geq C V \text { risk factors }\end{array}$ & $\mathrm{AHA}$ & - \\
\hline ITCA650 & $\geq 40$ & T2DM & $\geq 6.5 \%$ & $\begin{array}{l}\text { Pre-existing coronary, cerebro- } \\
\text { vascular or peripheral artery } \\
\text { disease }\end{array}$ & - & - \\
\hline DECLARE-TIMI & $\geq 40$ & T2DM & - & High risk CV events & - & - \\
\hline CARMELINA & $\geq 18$ & T2DM & $(6.5,10.0 \%)$ & High risk CV events & Drug naive or specific AHA & $\leq 45$ \\
\hline DEVOTE & $\geq 50$ & T2DM & $\leq 7.0 \%$ & $\begin{array}{l}\text { CVD or renal disease or } \geq 60 \\
C V \text { risk }\end{array}$ & Specific AHA & - \\
\hline MK-3102 & $\geq 40$ & T2DM & $(6.5,10.0 \%)$ & Pre-existing vascular disease & - & - \\
\hline VERTIS & $\geq 40$ & T2DM & $(7.0,10.5 \%)$ & Pre-existing vascular disease & Drug naive or AHA & $\geq 18$ \\
\hline CANVAS program & $\geq 40$ & T2DM & $(7.0,10.5 \%)$ & Pre-existing CVD or high CV risk & Drug naive or AHA & - \\
\hline Albiglutide trial & $\geq 40$ & T2DM & $>7.0 \%$ & CVD & - & - \\
\hline ACE & $\geq 65$ & Prediabetes & $5.9 \%$ & $\begin{array}{l}\text { CV event within the last } \\
3 \text { month }\end{array}$ & Drug naive & 25 \\
\hline
\end{tabular}


Table 3 Concomitant medication at baseline in CVOTs referred to in the text

\begin{tabular}{|c|c|c|c|c|c|c|c|c|c|}
\hline \multirow{2}{*}{$\begin{array}{l}\text { Concomitant } \\
\text { medication } \\
\text { @baseline }\end{array}$} & \multicolumn{3}{|c|}{ Antihyperglycaemic medication N (\%) } & \multicolumn{6}{|c|}{$\mathrm{CV}$ treatment $\mathrm{N}(\%)$} \\
\hline & Insulin & Metformin & $\begin{array}{l}\text { Sulphonyl- } \\
\text { urea }\end{array}$ & Aspirin & Statins & $\begin{array}{l}\text { Antiplatelet/ } \\
\text { anticoagu- } \\
\text { lant }\end{array}$ & $\begin{array}{l}\text { Beta- } \\
\text { blocker }\end{array}$ & ACEI/ARB & $\begin{array}{l}\text { Other anti- } \\
\text { hypertensives }\end{array}$ \\
\hline SAVOR-TIMI53 & $6757(40.9)$ & $11,094(67.4)$ & $6332(38.5)$ & $12,390(75.2)$ & $12,892(78.3)$ & $13,386(81.3)$ & $10,117(61.4)$ & $12,935(78.5)$ & $6730(40.9)$ \\
\hline EXAMINE & $1605(29.8)$ & $3562(66.2)$ & $2503(69.9)$ & $4881(90.7)$ & $4866(90.4)$ & $5232(97.2)$ & $4411(81.9)$ & $4411(81.9)$ & $1197(22.2)$ \\
\hline TECOS & $3408(23.2)$ & $11,966(81.6)$ & $6645(45.3)$ & $11,518(78.5)$ & $11,719(79.9)$ & $3167(21.7)$ & $9322(63.5)$ & $11,555(78.8)$ & 4961 (33.8) \\
\hline ELIXA & $2292(37.8)$ & $3834(63.2)$ & $1863(30.7)$ & $5726(94.4)$ & $5621(92.6)$ & $480(7.9)$ & $5119(84.4)$ & $5151(84.9)$ & $1327(21.9)$ \\
\hline $\begin{array}{l}\text { EMPA-REG } \\
\text { OUTCOME }\end{array}$ & $2374(34.0)^{\mathrm{a}}$ & $3933(55.9)^{\mathrm{a}}$ & $1383(19.6)$ & $5990(85)$ & $5387(77)$ & - & $4537(64)$ & $5651(80)$ & $2114(30)$ \\
\hline LEADER & $4159(45.0)^{\mathrm{a}}$ & 7136 (76.4) & $4721(50)$ & $5874(63)$ & $6729(72)$ & $6322(67.7)$ & $5173(55.4)$ & 7731 (83) & $920(9.85)$ \\
\hline SUSTAIN 6 & $1913(58.0)$ & $2414(73.2)$ & $1410(42.8)$ & 2108 (63.9) & 2399 (72.8) & $406(12.3)$ & $1894(57.4)$ & $2753(83.5)$ & $258(7.8)$ \\
\hline EXSCEL & $6836(46.3)$ & $11,295(76.6)$ & 5401 (36.6) & 9380 (63.6) & $10,845(73.5)$ & $10,835(73.5)$ & $8211(55.7)$ & $11,788(79.9)$ & \\
\hline DEVOTE & 6409 (83.9) & $4564(59.8)$ & $2229(29.2)$ & $4764(62.4)$ & $5972(78.2)$ & 1599 (20.9) & $4370(57.2)$ & $6182(80.9)$ & $2458(32.2)$ \\
\hline $\begin{array}{l}\text { CANVAS } \\
\text { program }\end{array}$ & $5095(50.2)$ & 7825 (77.2) & $4361(43)$ & - & 7599 (74.9) & 7466 (73.6) & $5421(53.5)$ & - & - \\
\hline ACE & - & - & - & $6131(94)$ & $6066(93)$ & $6384(98)$ & $4301(66)$ & 3839 (59) & - \\
\hline
\end{tabular}

a Both mono and dual therapy

their implications for the medication of type 2 diabetes mellitus (T2DM) patients.

\section{Summary of recently completed CVOTs}

In the past year, several CVOTs were completed, among them DEVOTE, ITCA650 (FREEDOM-CVO), the CANVAS program and very recently the EXSCEL and ACE trials. Four of these studies represent common drug classes for glucose-lowering medication in diabetes: basal insulin, GLP-1 RAs and SGLT-2 inhibitors. One study investigating the CVO of the DPP-4 inhibitor MK-3102 was terminated in March 2017. The DEVOTE study compared the CVO of the ultra-long-acting Insulin degludec with Insulin glargine U100 in T2DM patients with a high risk of $\mathrm{CV}$ events. The trial was designed to continue until the occurrence of at least 633 primary outcome events $[10,19]$. The CANVAS program comprises two sister trials that were combined to increase statistical power to assess CV safety and efficacy of canagliflozin. The original CANVAS design was adjusted after unblinding the trial for sub-group analysis in 2012. Because of the observed interim CVO results, a second separate study (CANVAS-R) was initiated. The inclusion criteria of CANVAS and CANVAS-R were almost identical. In addition to the primary MACE outcome the separate primary objective of CANVAS- $R$ is progression of albuminuria $[20,21]$. Two recently completed studies evaluated the CV risk of exenatide: EXSCEL and FREEDOM-CVO. EXSCEL, the largest GLP-1 RA study to date, analysed the influence of a once weekly subcutaneous injection of exenatide whereas in FREEDOM-CVO participants were continuously supplied with exenatide via an implanted mini pump (DUROS ${ }^{\circledR}$ ). Additionally, the ACE trial investigated whether the $\alpha$-glucosidase inhibitor acarbose could reduce $\mathrm{CV}$ events in a population with established coronary heart disease and newly detected impaired glucose tolerance. This population differed from those investigated in the other CVOTs which included T2DM patients. The original study design planned to investigate a three point MACE, which, due to too few events was extended to a five point MACE. The ACE study had the longest follow-up period of CVOTs summarized in this review (mean of 5 years $[22,23]$ ).

The major results of the completed CVOTs are summarized in the following sections, divided by $\mathrm{CV}$ outcomes: Primary MACE composite endpoint, all-cause mortality, myocardial infarction (MI), unstable angina (UA), $\mathrm{CV}$ death and heart failure (HF). Subsequently the safety endpoints renal events, pancreatitis, hypoglycaemic episodes and amputations will be reviewed (Table 4).

\section{Primary MACE composite endpoint}

The primary MACE of the recently completed studies comprised similar elements: CV death, MI and stroke. The ACE study additionally included UA and HF into the primary composite endpoint.

In the DEVOTE study, Insulin degludec was noninferior to Insulin glargine. Primary MACE occurred in $8.5 \%$ of the degludec group vs. $9.3 \%$ of the glargine group (HR 0.91; 95\% CI 0.78-1.06; $\mathrm{p}<0.001$ for non-inferiority [10]). Participants of the CANVAS program had a reduced risk of cardiovascular events when using canagliflozin in comparison to placebo. 26.9 vs. 31.5 participants per 1000 patient-years had an event comprised in the 


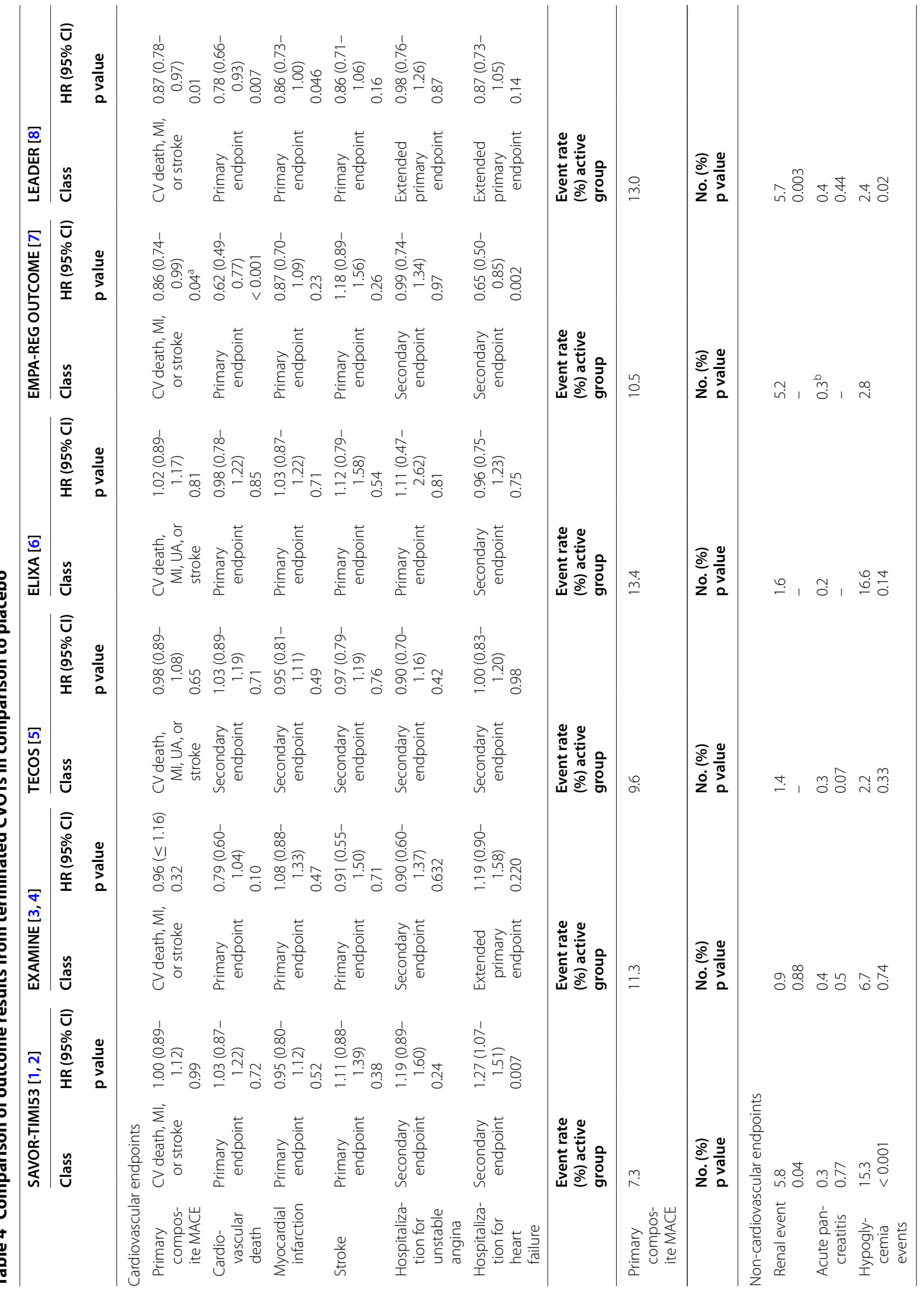




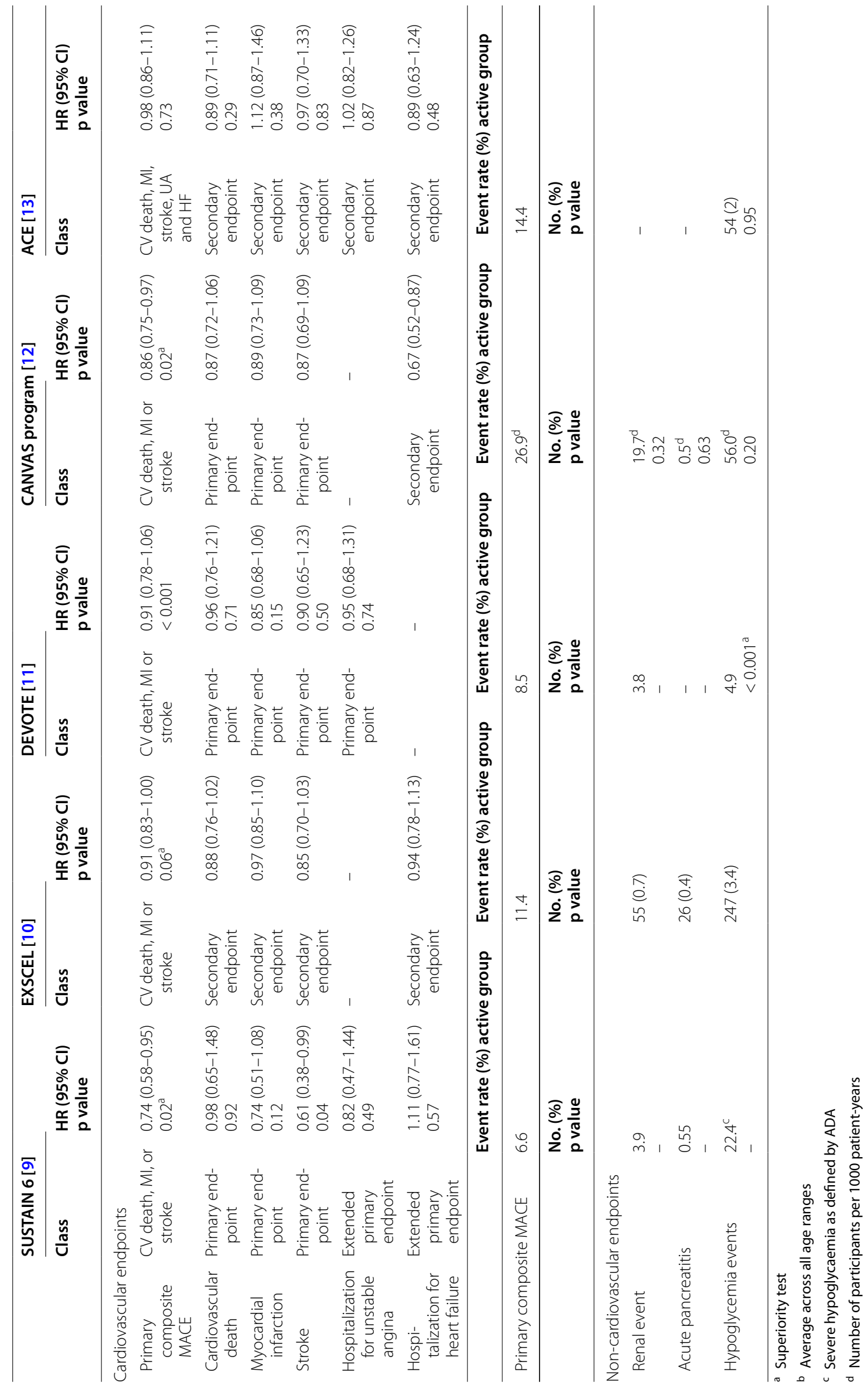


primary MACE (HR 0.86; 95\% CI 0.75-0.97; p < 0.001 for non-inferiority; $p=0.02$ for superiority [21]). In the EXSCEL study the primary composite outcome occurred in 839 of 7356 patients in the once-weekly exenatide group compared to 905 of 7396 patients in the placebo group (HR 0.91; 95\% CI 0.83-1.00). Thus, once-weekly exenatide was non-inferior with respect to safety but not superior with respect to efficacy $(\mathrm{p}<0.001$ for non-inferiority; $\mathrm{p}=0.06$ for superiority [24]). A total of 470 of 3272 (14.4\%) participants of the acarbose group in the ACE trial had a primary outcome event compared to 479 of $3250(14.7 \%)$ in the placebo group showing no reduction of CV risk (HR 0.98; 95\% CI 0.86-1.11; $\mathrm{p}=0.73$ [23]).

\section{All-cause mortality}

All-cause mortality was included in the secondary outcomes of DEVOTE and observed in 202 (5.3\%) participants of the degludec group in comparison to 221 (5.8\%) participants in the glargine group (HR 0.91; 95\% CI $0.76-1.11 ; \mathrm{p}=0.35)$, revealing no significant between group difference [10]. Treatment with canagliflozin did not result in a decrease of all-cause mortality, showing no superiority to placebo in the first secondary outcome of the CANVAS program (17.3 vs. $19.5 \mathrm{HR} 0.87$; $95 \% \mathrm{CI}$ 0.74-1.01; $\mathrm{p}=0.24$ [21]). In the EXSCEL trial all-cause mortality, a predefined secondary outcome, was $6.9 \%$ $(\mathrm{n}=507)$ in the once-weekly exenatide vs. $7.9 \%(\mathrm{n}=584)$ in the placebo groups, respectively (HR $0.86 ; 95 \%$ CI $0.77-0.97$ [24]. The ACE study could not demonstrate a significant difference between the treatment with acarbose or placebo with regard to all-cause mortality (216 (7\%) of 3272 vs. 219 (7\%) of 3250; HR 0.98; 95\% CI 0.81$1.19 ; \mathrm{p}=0.85[23])$.

\section{Cardiovascular death}

There was no significant difference in the occurrence of $\mathrm{CV}$ death comparing the two study groups confirming non-inferiority of Insulin degludec towards Insulin glargine (3.6\% vs. $3.7 \%$; HR 0.96; $95 \%$ CI $0.76-1.21 ; \mathrm{p}=0.71$ [10]). Participants treated with canagliflozin less often died from CV causes, but the difference was not significant (11.6 vs. 12.8 participants per 1000 patient-years; HR 0.87; 95\% CI 0.72-1.06; $\mathrm{p}=0.94$ [21]). In the EXSCEL trial $340(4.6 \%)$ patients died of CV causes in the onceweekly exenatide group whereas $383(5.2 \%)$ patients in the placebo group died as a result of $\mathrm{CV}$ events, showing no between group difference (HR 0.88; 95\% CI 0.76-1.02 [24]). The rate of CV related deaths in the ACE study was similar to EXSCEL. 4.4\% of patients died due to CV causes in the acarbose group and $5.0 \%$ in the placebo group. This between group difference was not considered to be significant (HR 0.89; 95\% CI 0.71-1.11; $\mathrm{p}=0.29$ [23]).

\section{Fatal and/or non-fatal MI}

Regarding the second component of the primary outcome, non-fatal MI, non-inferiority of Insulin degludec to Insulin glargine was confirmed $(3.8 \%$ vs. $4.4 \%$; HR 0.85 ; 95\% CI 0.68-1.06; $\mathrm{p}=0.15$ [10]). In the CANVAS program a decrease in fatal or non-fatal MI could be observed in the canagliflozin group compared to placebo, but again no statistical significance was determined (11.2 vs. 12.6 participants per 1000 patient-years; HR $0.87,95 \%$ CI 0.73-1.09 [21]). EXSCEL and ACE investigated fatal or non-fatal MI as a secondary outcome. In the onceweekly exenatide group 483 patients (6.6\%) and 493 patients $(6.7 \%)$ in the placebo group had a fatal or nonfatal MI showing no difference between the two treatment groups (HR 0.97; 95\% CI 0.85-1.10 [24]). In ACE the numbers of fatal or non-fatal MI were 122 (3.7\%) vs. 108 (3.3\%), indicating no significant difference in the treatment with acarbose and placebo (HR 1.12; 95\% CI $0.87-1.46 ; \mathrm{p}=0.38[23]$ ).

\section{Fatal and/or non-fatal stroke}

Non-inferiority was confirmed for Insulin degludec regarding the primary endpoint non-fatal stroke. $1.9 \%$ of patients in the degludec and $2.1 \%$ of patients in the glargine group had a non-fatal stroke (HR 0.90; 95\% CI 0.651.23; $\mathrm{p}=0.50[10])$. As observed for $\mathrm{CV}$ death and fatal or non-fatal MI, fatal and non-fatal stroke occurrences decreased with canagliflozin without showing significant differences to the placebo group (7.9 vs. 9.6 participants per 1000 patient-years; HR 0.87; 95\% CI 0.69-1.09 [21]). 187 patients $(2.5 \%)$ had a fatal or non-fatal stroke being treated once-weekly with exenatide in comparison to 218 patients $(2.9 \%)$ being given placebo. The number of events was not statistically different between the two groups (HR 0.85; 95\% CI 0.70-1.03 [24]). Similarly, treatment with acarbose did not reveal a reduction of stroke events compared to placebo ( $2.3 \%$ vs. $2.4 \%$; HR $0.97 ; 95 \%$ CI, 0.70-1.33; $\mathrm{p}=0.83$ [23]).

\section{Hospitalization for UA}

In the DEVOTE study, UA leading to hospitalization was included into the extended primary endpoint. In both groups, degludec and glargine, $1.9 \%$ of patients were hospitalized due to UA (HR 0.95; 95\% CI 0.68-1.31 [10]). The CANVAS program and EXSCEL did not analyse UA [21, 24]. In the ACE study hospital admission for UA was included in the five point MACE and independently investigated as a secondary outcome. 174 participants (5.3\%) were hospitalized for UA after being treated with acarbose and 170 participants of the placebo group (5.2\%; HR 1.02; 95\% CI 0.82-1.26; $\mathrm{p}=0.87$ ) revealing no different outcomes [23]. 


\section{Hospitalization for $\mathrm{HF}$}

The DEVOTE study did not provide information on hospitalization for HF, whereas the CANVAS program confirmed superiority of canagliflozin to placebo with 5.5 vs. 8.7 participants per 1000 patient-years (HR 0.67; 95\% CI 0.52-0.87 [21]). EXSCEL did not show a significant difference between the two treatment groups concerning hospitalization for HF: 219 patients $(3.0 \%)$ had an event when treated with once-weekly exenatide and 231 patients (3.1\%) when given placebo (HR 0.94; 95\% CI $0.78-1.13$ [24]). In ACE, 65 participants (2.0\%) of the acarbose group were hospitalized for HF and 73 participants $(2.2 \%)$ of the placebo group. This difference was also not significant (HR 0.89; 95\% CI 0.63-1.24; $\mathrm{p}=0.48$ [23]).

\section{Renal events and/or microvascular effects}

Adverse events associated with renal and urinary disorders were comparable between participants in the degludec and the glargine group in the DEVOTE study (3.8\% vs. $4.5 \%$ ) Acute kidney injury occurred in $1.8 \%$ of participants treated with Insulin degludec and in 2.5\% of participants treated with Insulin glargine [10]. As the CANVAS program includes CANVAS-R, renal outcomes were specifically analysed. Progression of albuminuria was defined as primary outcome, whereas Albuminuria regression was defined as secondary outcome. Albuminuria progression was less frequent in participants assigned to canagliflozin than placebo ( 89.4 vs. 128.7 participants with an event per 1000 patient-years; HR 0.73; 95\% CI 0.67-0.79). Regression of Albuminuria occurred more frequently in canagliflozin group than in the placebo group (293 vs. 188 participants with an event per 1000 patient-years; HR 1.70; 95\% CI 1.51-1.91) and renal-related adverse events were observed with an event rate of 20 vs. 17 per 1000 patient-years ( $\mathrm{p}=0.32$ [21]). EXSCEL classified renal events as "end stage renal failure needing chronic peritoneal/haemodialysis (including creation of fistula or other vascular access for haemodialysis) or renal transplantation". 55 of 7344 participants of the once-weekly exenatide group and 65 of 7389 participants of the placebo group had a renal event as classified above ( $0.7 \%$ vs. $0.9 \%$ [24]). In the ACE trial the incidence of impaired renal function was not different between the acarbose and the placebo groups (rate ratio $0.81 ; 95 \% \mathrm{CI}$ $0.54-1.23 ; \mathrm{p}=0.33$ [23]).

\section{Pancreatic effects}

Pancreatic effects were not analysed in the DEVOTE and ACE studies [10, 23]. In CANVAS there was no difference between canagliflozin and placebo regarding acute pancreatitis ( 0.5 vs. 0.4 events per 1000 patient-years, $\mathrm{p}$
0.63 [21]). The number of patients with an adverse pancreatic event were 26 in the once-weekly exenatide and 22 in the placebo group of the EXSCEL trial $(0.4 \%$ vs. $0.3 \%[24])$.

\section{Serious hypoglycaemic events}

The mean number of severe hypoglycaemic episodes as well as the number of nocturnal severe hypoglycaemic events was significantly reduced in participants in the Insulin degludec group compared to the Insulin glargine group $(4.9 \%$ vs. $6.6 \%$ of patients with severe hypoglycaemia; rate ratio 0.73 ; 95\% CI $0.60-0.89 ; \mathrm{p}<0.001$ for superiority; $1.0 \%$ vs. $1.9 \%$ of patients with nocturnal severe hypoglycaemia; rate ration 0.47 ; $95 \%$ CI $0.31-0.73$; $\mathrm{p}<0.001$ [10]). Participants of the CANVAS program had no higher risk of hypoglycaemia with canagliflozin than with placebo (50.0 vs. 46.4 events per 1000 patientyears; $p=0.20[21]$ ). This was also the case in participants of the EXSCEL trial: there was no difference in the rates of severe hypoglycaemia, neither when measuring only the first event (1.0 events per 100 patient-years in the once-weekly exenatide group and 0.9 events per 100 patient-years in the placebo group) nor when including recurrent events (1.6 events per 100 patient-years and 1.8 events per 100 patient-years [24]). There was also no between group difference in the rate of severe hypoglycaemic episodes in the ACE study (54 of 3272 (2\%) vs. 52 of 3250 (2\%) [23]).

\section{Amputations}

The number of amputations, although relatively infrequent, was significantly increased in the canagliflozin group compared to the placebo group. 6.3 vs. 3.4 participants per 1000 patient-years had an amputation primarily of a lower limb (HR 1.97, 95\% CI 1.41-2.75). Subgroup analysis revealed, that the higher risk was associated with a history of amputations or peripheral vascular disease and that the relative risk was comparable between subgroups [21]. In the DEVOTE and ACE studies, amputations were not listed as adverse events [10,23]. For the treatment with once-weekly exenatide a non-traumatic amputation was reported for 128 of 7344 participants (1.7\%). Similarly, 127 of 7389 participants (1.7\%) of the placebo group had to undergo non-traumatic amputation [24].

In addition to the CVOTs that were already completed this year we would like point out one other study that will give further insight into the $\mathrm{CV}$ effects of albiglutide, another GLP-1 RA. The albiglutide trial is estimated to be completed in 2018 and will compare the effect of $30 \mathrm{mg}$ albiglutide, $50 \mathrm{mg}$ albiglutide and placebo on CVOs in T2DM patients with CVD. 


\section{Discussion}

The new trials gave insights into the $\mathrm{CV}$ effects of the basal insulin degludec, the SGLT-2 inhibitor canagliflozin, the GLP-1 RA once-weekly exenatide and the $\alpha$-glucosidase inhibitor acarbose. Insulin degludec was compared to Insulin glargine U100. Since 2015 the new longer-acting Insulin glargine U300 has been approved for the European market, after initiation of DEVOTE. The DEVOTE study could confirm non-inferiority in terms of CV events. With regard to hypoglycaemic risks Insulin degludec was superior to Insulin glargine, both in rates of severe and nocturnal severe hypoglycaemia. Glycaemic control did not differ between the two groups. Also adverse events did not occur in different rates comparing Insulin degludec and Insulin glargine. Interestingly, it was reported that fasting glucose variability during the study was associated with higher risk of hypoglycaemia and of total mortality [25]. This observation is of interest because glucose variability has been suggested as an independent risk factor for diabetic complications [26]. Long lasting insulins provide patients with the possibility to consistently lower glucose levels. The more stable pharmacodynamics result in a half-life of more than $24 \mathrm{~h}$ and thereby reduce the risks of hypoglycaemia [27]. The DEVOTE study is only the second completed trial investigating $\mathrm{CV}$ effects of standard care medication like insulin, metformin or sulfonylurea. The ORIGIN trial compared CV outcomes of Insulin glargine with standard care and did not observe any differences between the two groups [9].

The CANVAS program displays a new approach, combining two studies after trial initiation. The combination of CANVAS and CANVAS-R increases participant numbers and statistical power. Additionally it enables the parallel analysis of separate primary objectives: CV outcomes and kidney disease progression. The combined CANVAS programs objective, superiority of canagliflozin towards placebo was achieved. Even though the primary endpoint was met with significant differences, the three components of the primary MACE endpoint- $\mathrm{CV}$ death, MI and stroke-only revealed minor benefits. In contrast to the separate primary outcomes, secondary outcomes like hospitalization for HF showed superiority for canagliflozin. Comparing the primary outcomes on CV risk of the SGLT-2 inhibitors canagliflozin and empagliflozin both showed superiority over placebo. Both agents had a positive effect on the progression of kidney disease [18, 21, 28]. The EMPA-REG OUTCOME study observed a significant risk reduction of microvascular outcome events which was mainly driven by a lower progression rate of kidney disease [28]. This possible benefit of SGLT-2 inhibitors on the progression rate of kidney disease was also observed in the CANVAS program
[21]. In contrast to empagliflozin, canagliflozin appeared to increase the rate of bone fractures (15.4 vs. 11.9 participants with fracture per 1000 patient-years; HR 1.26; 95\% CI 1.04-1.52 [21, 29] and amputations, prompting FDA and EMA to publish safety warnings [30-33]. The currently ongoing DECLARE-TIMI study will provide information on safety issues of dapagliflozin, enabling comparison with further SGLT-2 inhibitors. The contemporary analysis of real-world clinical practice CV-REAL included data from health records from six countries of patients that were newly started on SGLT-2 inhibitors and compared them with patients newly started on other glucose-lowering drugs. The SGLT-2 inhibitors varied according to countries included (canagliflozin, empagliflozin and dapagliflozin). This epidemiological study showed that the analysed SGLT-2 inhibitors can-in a real-world setting-reduce the risk of hospitalization for HF and of all-cause mortality by $39 \%$ and $51 \%$, respectively, when compared with other glucose-lowering drugs. This study provides complementary information on clinical trials of SGLT-2 inhibitors, namely EMPAREG OUTCOME and the CANVAS program [34]. In total, the results concerning CVOs of the CANVAS program are comparable to those published in previous studies for empagliflozin $[18,35]$.

EXSCEL adds information on glucose-lowering agents of the GLP-1 RA class to the already published ELIXA, LEADER and SUSTAIN-6 results. Once-weekly exenatide confirmed non-inferiority to placebo in regard of CV safety but was not seen as superior in regard of efficacy. This is comparable to lixisenatide in the ELIXA trial [15, 24]. Nevertheless once-weekly exenatide decreased allcause mortality by $14 \%$, a similar reduction as observed for liraglutide (15\% risk reduction of all-cause death), even though, by formal reasons, due to the lack of significant impact on the primary composite endpoint, could not in a hierarchical statistical analysis be accepted as formally significant $[16,24]$. No safety concerns were risen by any adverse events observed in the EXSCEL trial. A fifth GLP-1 RA, dulaglutide is currently tested for CV safety in the REWIND study, which is estimated to be completed in July 2018.

The ACE trial differed from the other presented CVOTs with regard to trial population. Pre-existing diabetes was an exclusion criterion and for inclusion participants required a history of CVD and impaired glucose tolerance. As this trial was conducted in China, trial population consisted to $97 \%$ of Han Chinese. It was shown, that acarbose was more effective in individuals consuming "Eastern" diets compared to "Western" diets. This might be a reason for the high number of prescriptions of acarbose in China, where it is the most common oral glucoselowering medication. It is also prescribed as preventative 
medication for individuals with impaired glucose tolerance (summarized in [36]). Designed as a CVOT with a three point MACE the ACE trial could not achieve enough events, resulting in an updated five point MACE (adding hospitalization for HF and UA) as primary outcome. The primary endpoint was not reduced comparing acarbose with placebo. Also most secondary outcomes did not show a difference between the two treatment groups. The number of participants which developed diabetes during the follow-up of the ACE study was reduced by $18 \%$ in the acarbose group compared to the placebo group. This risk reduction of incident diabetes in the high $\mathrm{CV}$ risk population supports the fact, that acarbose is frequently prescribed as prevention for individuals with impaired glucose tolerance [23]. Anyhow, it is worthy of interest that postprandial hyperglycaemia was not significantly different between the two groups in the last 3 years of the study [23].

The recent CVOT results summarized in this overview indicate, that the utilization of Insulin degludec as glucose-lowering medication is safe in regard to CVOs and adverse events. Even though canagliflozin could also confirm its CV safety a warning of FDA and EMA for adverse effects like amputations and fractures should be kept in mind [30, 31, 33]. Once-weekly exenatide demonstrated safety with regard to CVOs and adverse events. ACE could confirm, that acarbose can be used without safety concerns.

One major strength of the CANVAS program is that it is, so far, one of the longest CVOTs initiated after 2008. All four newly published CVOTs had large numbers of participants with high CV risk. Still, the limitations of CVOTs remain patient selection criteria, trial duration, short follow-up time, lack of head-to-head comparison with standard care as discussed previously [8]. Comparisons between different trials is difficult due to varying inclusion criteria, baseline characteristics and trial durations and this needs to be acknowledged when interpreting the outcome of such comparisons.

The "ESC Guidelines for the diagnosis and treatment of acute and chronic heart failure" commented that in patients with HF the treatment of choice should be metformin, especially because no $\mathrm{CV}$ data were available for DPP-4 inhibitors and GLP-1 RAs. The positive results on $\mathrm{CV}$ safety seen for empagliflozin were recognized in the ESC guidelines, and they gave a reminder, that no class effect should be subscribed to SGLT-2 inhibitors [37]. After the publication of these guidelines Rydén and colleagues expressed certain concerns on these suggestions and presented an update on ESC HF guidelines: "DPP-4 inhibitors (gliptins) increase plasma levels of incretins by inhibiting their breakdown, thereby augmenting insulin release. The drugs do not have any effect on cardiovascular events and, apart from the observations made with saxagliptin and alogliptin, there is no compelling evidence that this class of drugs affects heart failure. By contrast, long-acting GLP-1 receptor agonists act as incretin mimetics, improve glycaemic indices, and either have no effect on (lixisenatide) or seem to reduce (liraglutide and semaglutide) cardiovascular events, with no effect on hospital admissions for heart failure" [38].

Efforts are made to provide CVO information on the standard glucose-lowering agents insulin, metformin and sulfonylurea. A meta-analysis concluded, that a CV risk of metformin in T2DM patients could not be determined mainly due to the low amount of information currently available [39]. The REMOVAL trial recently investigated the influence of metformin on atherosclerosis progression in long-standing type 1 diabetes mellitus (T1DM) patients with high CV risk. Adding metformin to the insulin therapy and standard of care did not significantly affect atherosclerosis progression. However, metformin treatment had a positive effect on HbA1c, body weight and LDL-cholesterol [40, 41]. In addition to REMOVAL, the EMERALD study currently investigates the influence of metformin on CV function in adolescent T1DM patients and is bound to be completed in 2018 (NCT01808690).

Sulfonylureas have so far also not been analysed standalone regarding CV effects. The "Cardiovascular Outcomes in Participants with Type 2 Diabetes Mellitus" study, which compares CV outcomes of several drug classes (SGLT-2 inhibitors, GLP-1 RAs, DPP-4 inhibitors, Thiazolidinedione, Sulfonylureas and Insulin) could give further insight into this question. This study is estimated to be completed by the end of 2017 (NCT03249506). Nevertheless, studies like the currently published TOSCA-IT and the still running CAROLINA provide a head-to-head comparison of sulfonylureas with pioglitazone and the DDP-4 inhibitor linagliptin [42].

The large-scale study TOSCA-IT was initiated to compare the efficacy of pioglitazone, a PPAR- $\gamma$ agonist, and sulfonylurea as add-ons to metformin on $\mathrm{CV}$ outcomes. 3028 participants with inadequately controlled metformin monotherapy were randomized. The trial was designed as a Prospective Randomised Open Blinded Evaluation (PROBE) study, i.e. the event adjudicators were unaware of treatment assignment. The primary outcome was a composite of all-cause death, non-fatal MI, non-fatal stroke or urgent coronary revascularization. No significant differences between the two treatment groups-pioglitazone vs. sulfonylurea-could be observed in regard of the primary and secondary outcomes. The number of hypoglycaemic events was significantly lower and LDL-cholesterol levels higher in the pioglitazone than in the sulfonylurea group. These results 
suggest, that both drugs are suitable options as add-on treatment to metformin, with benefits for hypoglycaemia and LDL-cholesterol when using pioglitazone [43]. A previous CVOT with pioglitazone (PROactive) described a significant reduction of non-fatal $\mathrm{MI}$ and stroke in patients with T2DM and a high risk of macrovascular events. However, other end-points like heart failure showed a drastic increase in the pioglitazone group [44]. These results could not be confirmed by the TOSCA-IT study. Vaccaro and colleagues suggest, that these discrepancies arouse by the different outcomes assessed, the study populations and the choice of comparator. The low risk population of TOSCA-IT (only 11\% with CVD) could mask minor benefits of pioglitazone. Indeed, post hoc on-treatment results are in agreement with previous findings $[43,44]$.

Not only glucose-lowering medications are tested for $\mathrm{CV}$ safety. The therapeutic monoclonal antibody canakinumab targets interleukin- $1 \beta$ and is used as anti-inflammatory medication. Several observations suggest that a specific targeting of interleukin- $1 \beta$ could be used as secondary prevention of atherosclerotic events. Therefore CANTOS investigated the occurrence of non-fatal MI, non-fatal stoke or CV death as primary composite endpoint after the treatment with canakinumab. $40 \%$ of participants had a history of diabetes. Canakinumab could dose-dependently reduce the risk of $\mathrm{CV}$ events (primary and secondary endpoints) compared to placebo. All-cause mortality was comparable between the treatment groups, but patients of the canakinumab group died significantly more often due to infection or sepsis. These patients that died were more likely to have diabetes than those who did not die from infection [45].

Several additional trials ranging the most common glucose-lowering medications will be completed in the next 2 years. CAROLINA (estimated end date 03.2019) and CARMELINA (estimated end date 12.2017) will present information on the DPP-4 inhibitor linagliptin. The first CVOTs on DPP-4 inhibitors (SAVIOR-TIMI53, EXAMINE and TECOS) reported neutral effects on the composite MACE endpoint. SAVIOR-TIMI53 and EXAMINE however indicated an increase in risk of hospitalization for HF $[12,13]$. Three agents of the GLP-1 RA class have already been successfully tested for CV safety (liraglutide, lixisenatide and semaglutide [16, 17, 44]). Also once-weekly exenatide is safe with regard to CVOs. Two currently ongoing studies will present the results for further agents in the next year: REWIND (dulaglutide) and the albiglutide trial (albiglutide). SGLT-2 inhibitors are a relatively new class of glucose-lowering drugs. Therefore, several trials on CVO are currently running and will be completed in 2019 (DECLARE-TIMI-dapagliflozin and VERTIS-ertugliflozin) to add new information on further agents to the results obtained in the EMPA-REG OUTCOME study and the CANVAS program. With regard of the new CVOT results, empagliflozin, liraglutide and semaglutide remain the preferred second- and third-line medication in patients with T2DM adding canagliflozin as an additional option [46].

\section{Conclusion}

Important CVOTs assessing CV safety of glucose-lowering medication were completed and presented in 2017. They reached their primary outcomes and confirmed previous studies that indicated no increased CV risk of glucose-lowering drugs. Insulin degludec showed noninferiority to Insulin glargine (DEVOTE). The CANVAS program demonstrated superiority of canagliflozin to placebo in the primary endpoint. Once-weekly exenatide (EXSCEL) and acarbose (ACE) were non-inferior to placebo and no safety concerns were raised by the presented results. Many additional CVOTs are estimated to be completed within the next 2 years and will provide additional insights into CV safety of glucose-lowering drugs.

\section{Abbreviations}

D\&CVD: diabetes \& cardiovascular disease; EASD: European Association for the Study of Diabetes; CV: cardiovascular; CVD: cardiovascular disease; FDA: Food and Drug Administration; EMA: European medicine agency; HR: hazard ration; Cl: confidence interval; CVOT: cardiovascular outcome trial; DPP-4: dipeptidylpeptidase-4; SGLT-2: sodium-glucose cotransporter-2; GLP-1: glucagon-likepeptide-1; RA: receptor agonist; T2DM: type 2 diabetes mellitus; MACE: major adverse cardiovascular event; MI: myocardial infarction; UA: unstable angina; HF: heart failure; T1DM: type 1 diabetes mellitus; LDL: low density lipoprotein; ESC: European Society of Cardiology; PPAR: peroxisome proliferator-activated receptor; ACS: acute coronary syndrome; AHA: anti-hyperglycaemic agent; ACEl: angiotensin-converting-enzyme inhibitor; ARB: angiotensin-receptor blocker; ADA: American Diabetes Association; CVO: Cardiovascular outcome.

\section{Authors' contributions}

OS was responsible for conception and design, drafting of the manuscript, and the final approval of the version to be published. ES, LR and AC contributed specialized input especially regarding their fields of expertise, and critically revised the manuscript. All authors read and approved the final manuscript.

\section{Author details \\ ${ }^{1}$ Forschergruppe Diabetes e. V., Ingolstaedter Landstraße 1, Neuherberg, 85764 Munich, Germany. ${ }^{2}$ Cardiology Unit, Department of Medicine K2, Karolinska Institute, 17176 Stockholm, Sweden. ${ }^{3}$ Institut d'Investigacions Biomèdiques August Pi i Sunyer (IDIBAPS) and Centro de Investigación, Biomedica en Red de Diabetes y Enfermedades Metabólicas Asociadas (CIBERDEM), Barcelona, Spain. ${ }^{4}$ Department of Cardiovascular and Meta- bolic Diseases, IRCCS Multimedica Sesto San Giovanni, Via Milanese 300, 20099 Milan, Italy.}

\section{Acknowledgements}

We thank Dr. K. Fritzen for her involvement in our scientific discussions, and support on manuscript edition and formatting.

\section{Competing interests}

L.R has been a member of advisory boards and/or speaker for AstraZeneca, Bayer, Boehringer-Ingelheim, Sanofi; and received research support from the Swedish Heart-Lung Foundation, Swedish Diabetes Foundation, Karolinska 
Institutet, Private Foundations, Stockholm County Council, Swedish Medical Assembly, Bayer and Boehringer-Ingelheim. E.S. has received lecturing honoraria and consultation fees from AstraZeneca, Bayer, Boehringer Ingelheim, Merck-Serono, MSD/Merck, Novartis, Sanofi. A.C. has been a member of advisory boards for Astra Zeneca, Bayer Healthcare, Boehringer Ingelheim, Bristol Myers Squibb, Danone, DOC Generici, Eli Lilly, Janssen, Medtronic, Merck Sharp \& Dome, Novartis, Novo Nordisk, OM Pharma, Roche Diagnostics, Sanofi, Takeda and Unilever; has been a consultant for Bayer Pharma, Lifescan, Mendor, Novartis and Roche Diagnostics; given lectures for Astra Zeneca, Bayer Healthcare, Bayer Pharma, Boehringer Ingelheim, Bristol Myers Squibb, Eli Lilly, Merck Sharp \& Dome, Mitsubishi, Novartis, Novo Nordisk, Nutricia, Sanofi, Servier and Takeda; and received research grants from Mitsubishi, Novartis and Novo Nordisk. O.S. has acted as member of advisory boards and/ or given lectures under support from Abbott, Astra Zeneca, Bayer Healthcare, Boehringer-Ingelheim, Eli Lilly, Medtronic, Novartis, Roche Diagnostics, Sanofi; and is CEO and founder of Sciarc $\mathrm{GmbH}$.

\section{Availability of data and materials}

Data sharing not applicable to this article as no datasets were generated during the current study.

\section{Consent for publication}

Not applicable.

Ethics approval and consent to participate

Not applicable.

\section{Funding}

No funding supported the generation of this manuscript.

\section{Publisher's Note}

Springer Nature remains neutral with regard to jurisdictional claims in published maps and institutional affiliations.

Received: 26 September 2017 Accepted: 3 October 2017 Published online: 11 October 2017

\section{References}

1. Dailey G. Overall mortality in diabetes mellitus: where do we stand today? Diabetes Technol Ther. 2011;13(Suppl 1):S65-74.

2. Barnett KN, et al. A 12-year follow-up study of all-cause and cardiovascular mortality among 10,532 people newly diagnosed with Type 2 diabetes in Tayside, Scotland. Diabet Med. 2010;27(10):1124-9.

3. Holman RR, et al. 10-year follow-up of intensive glucose control in type 2 diabetes. N Engl J Med. 2008;359(15):1577-89.

4. Bergenstal RM. Glycemic variability and diabetes complications: does it matter? Simply put, there are better glycemic markers! Diabetes Care. 2015;38(8):1615-21.

5. FDA. Guidance for industry diabetes mellitus - evaluating cardiovascular risk in new antidiabetic therapies to treat type 2 diabetes. Silver Spring: FDA; 2008.

6. EMA. Guideline on clinical investigation of medicinal products in the treatment or prevention of diabetes mellitus. London: EMA; 2012.

7. Hirshberg B, Raz I. Impact of the US Food and Drug Administration cardiovascular assessment requirements on the development of novel antidiabetes drugs. Diabetes Care. 2011;34(Suppl 2):S101-6.

8. Schnell $\mathrm{O}$, et al. Current perspectives on cardiovascular outcome trials in diabetes. Cardiovasc Diabetol. 2016;15(1):139.

9. Gerstein $\mathrm{HC}$, et al. Basal insulin and cardiovascular and other outcomes in dysglycemia. N Engl J Med. 2012;367(4):319-28.

10. Marso SP, et al. Efficacy and safety of degludec versus glargine in Type 2 diabetes. N Engl J Med. 2017;377(8):723-32.

11. Regier EE, Venkat MV, Close KL. More than 7 years of hindsight: revisiting the FDA's 2008 guidance on cardiovascular outcomes trials for Type 2 diabetes medications. Clin Diabetes. 2016;34(4):173-80.

12. Scirica BM, et al. Saxagliptin and cardiovascular outcomes in patients with type 2 diabetes mellitus. N Engl J Med. 2013;369(14):1317-26.
13. White WB, et al. Alogliptin after acute coronary syndrome in patients with type 2 diabetes. N Engl J Med. 2013;369(14):1327-35.

14. Green JB, et al. Effect of sitagliptin on cardiovascular outcomes in Type 2 diabetes. N Engl J Med. 2015;373(3):232-42.

15. Pfeffer MA, et al. Lixisenatide in patients with Type 2 diabetes and acute coronary syndrome. N Engl J Med. 2015;373(23):2247-57.

16. Marso SP, et al. Liraglutide and cardiovascular outcomes in Type 2 diabetes. N Engl J Med. 2016;375(4):311-22.

17. Marso SP, et al. Semaglutide and cardiovascular outcomes in patients with Type 2 diabetes. N Engl J Med. 2016;375(19):1834-44.

18. Zinman B, et al. Empagliflozin, cardiovascular outcomes, and mortality in Type 2 diabetes. N Engl J Med. 2015;373(22):2117-28.

19. Marso SP, et al. Design of DEVOTE (trial comparing cardiovascular safety of insulin degludec vs insulin glargine in patients with type 2 diabetes at high risk of cardiovascular events) —DEVOTE 1. Am Heart J. 2016;179:175-83.

20. Neal B, et al. Optimizing the analysis strategy for the CANVAS Program: a prespecified plan for the integrated analyses of the CANVAS and CANVAS-R trials. Diabetes Obes Metab. 2017;19(7):926-35.

21. Neal B, et al. Canagliflozin and cardiovascular and renal events in Type 2 diabetes. N Engl J Med. 2017;377(7):644-57.

22. Holman RR, et al. Rationale for and design of the acarbose cardiovascular evaluation (ACE) trial. Am Heart J. 2014;168(1):23-9.

23. Holman RR, et al. Effects of acarbose on cardiovascular and diabetes outcomes in patients with coronary heart disease and impaired glucose tolerance (ACE): a randomised, double-blind, placebo-controlled trial. Lancet Diabetes Endocrinol. 2017. pii: S2213-8587(17)30309-1.

24. Holman RR, et al. Effects of once-weekly exenatide on cardiovascular outcomes in Type 2 diabetes. N Engl J Med. 2017;377(13):1228-39.

25. Zinman B, et al. Day-to-day fasting glycaemic variability in DEVOTE: associations with severe hypoglycaemia and cardiovascular outcomes (DEVOTE 2). Diabetologia. 2017. doi:10.1007/s00125-017-4423-z.

26. Frontoni $S$, et al. Glucose variability: an emerging target for the treatment of diabetes mellitus. Diabetes Res Clin Pract. 2013;102(2):86-95.

27. Heise T, et al. Lower within-subject variability of insulin detemir in comparison to NPH insulin and insulin glargine in people with type 1 diabetes. Diabetes. 2004:53(6):1614-20.

28. Wanner $C$, et al. Empagliflozin and progression of kidney disease in Type 2 diabetes. N Engl J Med. 2016;375(4):323-34.

29. Watts $N B$, et al. Effects of canagliflozin on fracture risk in patients With Type 2 diabetes mellitus. J Clin Endocrinol Metab. 2016;101(1):157-66.

30. FDA Drug Safety Communication. FDA revises label of diabetes drug canagliflozin (Invokana, Invokamet) to include updates on bone fracture risk and new information on decreased bone mineral density; 2015.

31. FDA Drug Safety Communications. FDA confirms increased risk of leg and foot amputations with the diabetes medicine canagliflozin (Invokana, Invokamet, Invokamet XR). Silver Spring: FDA Drug Safety Communications; 2016

32. Fadini GP, Avogaro A. SGTL2 inhibitors and amputations in the US FDA adverse event reporting system. Lancet Diabetes Endocrinol. 2017:5(9):680-1.

33. Agency EM. SGLT-2 inhibitors: information on potential risk of toe amputation to be included in prescribing information; 2017.

34. Kosiborod M, et al. Lower risk of heart failure and death in patients initiated on SGLT-2 inhibitors versus other glucose-lowering drugs: the CVD-REAL study. Circulation. 2017;136(3):249-59.

35. Wu JH, et al. Effects of sodium-glucose cotransporter-2 inhibitors on cardiovascular events, death, and major safety outcomes in adults with type 2 diabetes: a systematic review and meta-analysis. Lancet Diabetes Endocrinol. 2016:4(5):411-9.

36. Standl E, et al. On the potential of acarbose to reduce cardiovascular disease. Cardiovasc Diabetol. 2014;13:81.

37. Ponikowski P, et al. 2016 ESC guidelines for the diagnosis and treatment of acute and chronic heart failure. Rev Esp Cardiol (Engl Ed). 2016;69(12):1167.

38. Rydén L, et al. Corrections needed to 2016 ESC guideline and AHA scientific statement on heart failure. Lancet Diabetes Endocrinol. 2017;5(5):325-6.

39. Griffin SJ, Leaver JK, Irving GJ. Impact of metformin on cardiovascular disease: a meta-analysis of randomised trials among people with type 2 diabetes. Diabetologia. 2017. doi:10.1007/s00125-017-4337-9. 
40. Petrie JR, et al. Cardiovascular and metabolic effects of metformin in patients with type 1 diabetes (REMOVAL): a double-blind, randomised, placebo-controlled trial. Lancet Diabetes Endocrinol. 2017;5(8):597-609.

41. Standl E. Metformin in type 1 diabetes. Lancet Diabetes Endocrinol. 2017;5:567-9.

42. Vaccaro O, et al. The TOSCA.IT trial: a study designed to evaluate the effect of pioglitazone versus sulfonylureas on cardiovascular disease in type 2 diabetes. Diabetes Care. 2012;35(12):e82.

43. Vaccaro $\mathrm{O}$, et al. Effects on the incidence of cardiovascular events of the addition of pioglitazone versus sulfonylureas in patients with type 2 diabetes inadequately controlled with metformin (TOSCA.IT): a randomised, multicentre trial. Lancet Diabetes Endocrinol. 2017;35(12):e82.

44. Dormandy JA, et al. Secondary prevention of macrovascular events in patients with type 2 diabetes in the PROactive Study (PROspective pioglitAzone Clinical Trial In macroVascular Events): a randomised controlled trial. Lancet. 2005;366(9493):1279-89.
45. Ridker PM, et al. Antiinflammatory therapy with canakinumab for atherosclerotic disease. N Engl J Med. 2017;377(12):1119-31.

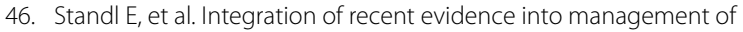
patients with atherosclerotic cardiovascular disease and type 2 diabetes. Lancet Diabetes Endocrinol. 2017;5(5):391-402.

47. Leiter LA, et al. Efficacy and safety of saxagliptin in older participants in the SAVOR-TIMI 53 trial. Diabetes Care. 2015;38(6):1145-53.

48. Zannad F, et al. Heart failure and mortality outcomes in patients with type 2 diabetes taking alogliptin versus placebo in EXAMINE: a multicentre, randomised, double-blind trial. Lancet. 2015;385(9982):2067-76.

49. Marso SP, et al. Liraglutide and cardiovascular outcomes in Type 2 diabetes. N Engl J Med. 2016;375(4):311-22

50. Marso SP, et al. Semaglutide and cardiovascular outcomes in patients with Type 2 diabetes. N Engl J Med. 2016;375(19):1834-44.

\section{Submit your next manuscript to BioMed Central and we will help you at every step:}

- We accept pre-submission inquiries

- Our selector tool helps you to find the most relevant journal

- We provide round the clock customer support

- Convenient online submission

- Thorough peer review

- Inclusion in PubMed and all major indexing services

- Maximum visibility for your research

Submit your manuscript at www.biomedcentral.com/submit 